\title{
Potentiation of atherosclerotic lesions in rabbits by a high dietary level of vitamin $E$
}

\author{
BY SUSAN L. GODFRIED ${ }^{1}$, GERALD F. COMBS JR ${ }^{1,2, *}$, \\ JAMES M. SAROK A ${ }^{1}$ AND LLOYDA. DILLINGHA M ${ }^{3}$ \\ ${ }^{1}$ Department of Poultry and Avian Sciences, ${ }^{2}$ Division of Nutritional Sciences, and \\ ${ }^{3}$ Center for Research, Animal Resources, Cornell University, Ithaca, NY 14853, USA
}

(Received 15 March 1988 - Accepted 7 October 1988)

1. Two experiments were conducted to determine whether or not high dietary levels of vitamin $\mathrm{E}$ affect the development of atherosclerotic lesions in aortas of cholesterol-fed $(5 \mathrm{~g} / \mathrm{kg}$ diet $)$ rabbits that were mechanically deendothelialized by balloon catheterization.

2. In the first experiment, the aortas of rabbits fed $2000 \mathrm{mg}$ vitamin $\mathrm{E} / \mathrm{kg}$ diet (i.e. 50 -fold their nutritional requirement) for 8 weeks showed no gross morphological differences, either within or outside experimentally damaged areas, from those of rabbits fed the nutritionally adequate control level $(40 \mathrm{mg} / \mathrm{kg})$ of the vitamin.

3. In the second experiment, rabbits fed $10000 \mathrm{mg}$ vitamin $\mathrm{E} / \mathrm{kg}$ diet (i.e. 250 -fold requirement) for 1415 weeks showed significantly greater endothelial loss and plaque formation at aortic sites outside of the mechanically damaged area than did controls. Plasma cholesterol levels were very high $(9000-14000 \mathrm{mg} / \mathrm{l})$ and were not affected by dietary vitamin $E$ level until $10-12$ weeks when they were reduced moderately $(18 \%)$.

4. It is concluded that very high levels of vitamin $E$ can potentiate spontaneous atherosclerotic lesions, and it is suggested that this effect may depend on high cholesterol status.

Several lines of evidence indicate that vitamin E, at levels above those normally regarded as being nutritionally required, can enhance wound healing. Kim \& Shklar (1983) found that daily administration of $60 \mathrm{mg} \mathrm{D}$ - $\alpha$-tocopheryl acetate to apparently vitamin $\mathrm{E}$ adequate rats increased the rate of healing of gingival wounds. Gravitational ulcers in human beings have been reported to be reduced or healed by vitamin E therapy (Lee, 1953; Marks, 1962). In addition to accelerating healing, high levels of vitamin $E$ have been shown to reduce collagen accumulations and, thus, scar tissue formation at the wound site. Ehrlich et al. (1972) found that a high level $(190 \mathrm{mg})$ of vitamin $\mathrm{E}$ administered by injection into surgically created wounds of rats significantly reduced post-surgical scarring as indicated by a decrease in collagen accumulation and wound tensile strength. Kagoma et al. (1985) found that a high dietary supplement $(300 \mathrm{mg} / \mathrm{kg}$ diet $)$ of vitamin $\mathrm{E}$ reduced the incidence and degree of experimentally induced peritoneal adhesions in mice. Baker (1981) reported that patients given a daily oral supplement of $1000 \mathrm{mg}$ vitamin $E$ for 1 year after breast augmentation surgery experienced a significantly reduced incidence of spherical contractures around implants compared with patients not given the supplement.

The mechanisms by which vitamin $\mathrm{E}$ affects wound healing are not clear but may involve anti-inflammatory activity of the vitamin. It is known that the duration of the later stages of wound healing and scarring are related to that of the inflammatory stage (Dunphy, 1974). Vitamin E has been shown to be anti-inflammatory (Stuyvesant \& Jolley, 1967; Kamimura, 1972); this probably involves its activity in membrane stabilization (Lucy, 1978) (e.g. decreasing lysosomal enzyme release, decreasing histamine release from mast cells and serotonin release from tissue cells), or in affecting prostaglandin metabolism (Forester, 1980; Okuma et al. 1980; Karpen et al. 1981; Chan et al. 1986) and platelet aggregation (Okuma et al. 1971; Fong, 1976; Steiner, 1978) (e.g. reducing thrombus formation and facilitating wound perfusion), or both.

$$
\text { * For reprints. }
$$


The potential of vitamin $\mathrm{E}$ to enhance wound healing suggested that it may reduce atherosclerotic plaque formation in spontaneously or mechanically damaged arteries. According to the response to injury hypothesis proposed by Ross \& Glomset (1978), damage to the vascular epithelium leads to plaque formation through platelet aggregation, lipid accumulation, smooth-muscle proliferation and connective-tissue formation. The lipid-accumulation phase of this process is enhanced by hypercholesterolaemia (Depalma et al. 1970). High dietary levels of vitamin $\mathrm{E}$ have been shown to reduce plasma levels of cholesterol or total lipids in rabbits (Wilson et al. 1978; Viswanathan et al. 1979; Westrope et al. 1982; Komaratat et al. 1985) and rats (Chen et al. 1972; Yang \& Desai, 1977 b), or both, and to reduce atherogenesis in rabbits (Wilson et al. 1978; Westrope et al. 1982) and Japanese quails (Coturnix coturnix japonica) (Donaldson, 1982). It has also been suggested that superoxide-dependent lipid peroxidation may be involved in atherogenesis (Heinecke et al. 1986). Therefore, it is possible that, through one or more mechanisms, vitamin $\mathrm{E}$ may inhibit atherogenesis in damaged arteries.

The present study undertook to test the hypothesis that high dietary levels of vitamin $\mathrm{E}$ can reduce the incidence or severity of atherosclerotic lesions or both. The animal model used was the balloon catheter de-endothelialized, cholesterol-fed rabbit. Stemerman (1973) showed that mechanical damage to rabbit aortas created by this means produces intimal changes similar to the pre-atherosclerotic fibromuscular plaques of human beings. Such lesions in hypercholesterolaemic rabbits have been shown to be highly susceptible to lipid deposition (Friedman \& Byers, 1965; Minick et al. 1977; Schwenke, 1985).

\section{MATERIALS AND METHODS}

\section{Animals and diets}

Twenty-four weanling male and female Flemish Giant Chinchilla Cross rabbits (Department of Laboratory Animal Services, New York State College of Veterinary Medicine, Cornell University, Ithaca, NY) were used in the first experiment, and twelve weanling male New Zealand White rabbits (S\&L Rabbitry, Romulus, NY) were used in the second experiment. Rabbits were housed individually in stainless steel, wire-bottomed cages $(300 \mathrm{~mm} \times 610 \mathrm{~mm} \times 610 \mathrm{~mm})$ in a room with controlled temperature and humidity and a regular photoperiod ( $12 \mathrm{~h}$ light $-12 \mathrm{~h}$ dark). Each rabbit consumed about $140 \mathrm{~g}$ feed/d and was weighed weekly; water was provided $a d l i b$. The general health condition of each rabbit was assessed three to five times per week by evaluation of general appearance and activity, and by gross examination of faeces.

Rabbits were fed a non-purified basal diet (Table 1) modified after that of the National Research Council (1977) for rabbits weighing $0.5-4 \mathrm{~kg}$. The dry ingredients of the basal diet were mixed in batches bimonthly and stored at $4^{\circ}$; on a monthly basis, vitamin E (as all-rac- $\alpha$-tocopherol acetate (Roche Chemical Division, Hoffmann-La Roche, Inc., Nutley, NJ)), cholesterol acetate (Sigma Chemical Co., St Louis, MO) and refined maize oil were added to these premixed batches as indicated in Table 1 , and the resulting diets were pelleted using a hot-water-heated laboratory pellet mill. Batches of 2 weeks' supplies of the pelleted diets were stored at room temperature before use. In each experiment half the rabbits were fed the basal diet supplemented with $40 \mathrm{mg}$ all-rac- $\alpha$-tocopheryl acetate $/ \mathrm{kg}$ diet (i.e. the National Research Council (1977) suggested level for rabbits) to ensure vitamin $\mathrm{E}$ adequacy; the other groups were fed on much higher levels (i.e. $2000 \mathrm{mg} / \mathrm{kg}$ in Expt 1; $10000 \mathrm{mg} / \mathrm{kg}$ in Expt 2) of the vitamin. 
Table 1. Composition of basal diet for rabbits $(\mathrm{g} / \mathrm{kg})$

\begin{tabular}{lc}
\hline \hline Ingredient & \\
& \\
Lucerne (Medicago sativa) meal, dehydrated, $170 \mathrm{~g}$ protein $/ \mathrm{kg}$ & $490 \cdot 0$ \\
Barley, ground & $230 \cdot 0$ \\
Soya-bean meal, $440 \mathrm{~g}$ protein $/ \mathrm{kg}$ & $110 \cdot 0$ \\
Wheat bran & $100 \cdot 0$ \\
Maize oil, refined & $45 \cdot 0$ \\
Salt, iodized & $4 \cdot 0$ \\
Vitamin-mineral premix* & $5 \cdot 0$ \\
DL-Methionine, $980 \mathrm{~g} / \mathrm{kg}$ & $5 \cdot 0$ \\
Cholesteryl acetate & $5 \cdot 0$ \\
\hline \hline
\end{tabular}

* Provided (mg/kg diet) the following: vitamin A (all-trans-retinyl palmitate) 600 , vitamin $\mathrm{D}_{3} 200$, vitamin $\mathrm{B}_{12}$ $0 \cdot 02$, nicotinic acid 140 , pyridoxine hydrochloride $35, \mathrm{Na}_{2} \mathrm{SeO}_{3} 0 \cdot 4, \mathrm{CuSO}_{4} \cdot 5 \mathrm{H}_{2} \mathrm{O} 35, \mathrm{ZnO} 160$, maize meal to make $5 \mathrm{~g}$.

\section{Aortic endothelial removal}

At $2-3$ weeks after the beginning of feeding the experimental diets, localized removal of the mid-thoracic aortic endothelium was accomplished using a balloon catheter according to the method of Schwenke (1985). In preparation for this procedure, each rabbit was anaesthetized with intramuscular injections of $35 \mathrm{mg}$ Ketaset (Bristol Veterinary Products, Bristol Laboratories, Syracuse, NY) and $5 \mathrm{mg}$ Rompun (Haver, Bayvet Division, Miles Laboratories Inc., Shawnee, KS) $/ \mathrm{kg}$ body-weight. Isofluorane gas (Expt 1) or a supplemental dose of Ketaset $(17.5 \mathrm{mg} / \mathrm{kg}$ body-weight) (Expt 2) was given during surgery if there was any possibility of a rabbit feeling pain. The right femoral artery was exposed and a 4F Fogerty embolectomy catheter (American V. Meueller, McGraw Park, IL) (fitted with a $1.0 \mathrm{ml}$ syringe) was inserted up the artery into the mid-thoracic aorta. The catheter balloon was inflated using $0.6 \mathrm{ml}$ sterile saline $(9 \mathrm{~g}$ sodium chloride/l), and the inflated catheter was slowly pulled distally for a distance of $40 \mathrm{~mm}$. The balloon was then deflated and, in Expt 1 only, the catheter was repositioned $60 \mathrm{~mm}$ distally at which point the balloon was again inflated using $0.4 \mathrm{ml}$ sterile saline and was pulled distally for a distance of $40 \mathrm{~mm}$. The catheter was deflated and removed, and the femoral artery was ligated. The surgical incision was closed in a routine manner. Sham-operated rabbits (Expt 1 only) were treated as described, with insertion of the catheter, but the balloon was not inflated. After the procedure, surface wounds were observed daily for 2 weeks and sporadically thereafter.

\section{Evaluation of aortic morphology}

In Expt 1, the gross morphological appearances of the aortas were evaluated 5 weeks after surgery. Rabbits were killed using an intravenous injection of T-61 (American Hoechst Corp., Animal Health Division, Somerville, NJ) following an intravenous injection of heparin (100 mg, grade I, sodium salt) into the ear vein. On death, each rabbit was perfused through the left ventricle with saline followed by $10 \%$ neutral-buffered formalin. The aortas were removed, opened sagitally and fixed in neutral-buffered formalin. Each fixed aorta was later scored visually by an observer naive to the treatments according to the following system: 0 normal, 1 light patchy, 2 moderate patchy, 3 light diffuse streaks, 4 moderate diffuse streaks, 5 severe streaks, 6 very severe streaks. The extent of aortic damage was approximated by multiplying the score for each discernible area of damage by the length of the area.

In Expt 2, aortas were examined 12 weeks after surgery. At $0.5 \mathrm{~h}$ before death each rabbit 
was tranquilized with Ketaset $(15 \mathrm{mg} / \mathrm{kg}$ body-weight, intramuscularly); then, Evans blue ( $4 \mathrm{ml}$ saline $(10 \mathrm{~g} \mathrm{NaCl} / 1) / \mathrm{kg}$ body-weight) and heparin ( $100 \mathrm{mg}$; grade I, sodium salt) were injected by ear vein. Rabbits were killed with T-61 after which samples of liver and left femoral artery were quickly removed and placed in liquid nitrogen. These specimens were stored at $-75^{\circ}$ for subsequent analyses of $\alpha$-tocopherol and (liver only) total vitamin A. Each rabbit was then perfused through the left ventricle with saline followed by neutralbuffered formalin; then the aorta was prepared as described previously. The percentage of aortic surface area that stained positively for collagen in vivo was measured by tracing on to paper the outlines of both the total aortic and Evans blue-stained areas using a projecting microscope. Quantification was accomplished by weighing the cut-out paper tracings; results were expressed as the percentage of total area that was de-endothelialized.

The in vivo Evans blue-stained, fixed aortas were then stained for lipids according to a modification of the procedure of Holman et al. (1958). This procedure involved immersion of the arteries in $70 \%$ ethanol for $15 \mathrm{~min}$, followed by their immersion in Herxheimer staining solution $(0.5 \%$ Sudan III in $35 \%$ ethanol-50\% acetone) for $20 \mathrm{~min}$ at room temperature, during which time they were agitated periodically to prevent irregular staining. After staining, the aortas were differentiated in $85 \%$ ethanol for $20 \mathrm{~min}$, and were then rinsed in running tap-water for $1 \mathrm{~h}$.

The relative area of lipid plaque in each aorta was evaluated by measuring the percentage of aortic area stained by Sudan III in the same manner as described for the measurement of the Evans blue-stained areas. Results were expressed as the percentage of aortic area covered by plaque.

\section{Histological examination of aortas}

In Expt 2 cross-sectional pieces were taken from each thoracic aorta at each of four locations: (1) the arch, (2) above the site of balloon injury and below the arch, (3) within the area of balloon injury, (4) below the site of balloon injury. Tissue specimens were fixed in neutral-buffered formalin and were embedded in paraffin; 6- $\mu \mathrm{m}$ sections were stained with haematoxylin and eosin (H\&E) for routine examination or with Masson's trichrome to visualize elastin and collagen. The region of aorta with greatest plaque (tunica intima) thickness was identified by viewing the H\&E-stained sections. Maximum plaque thickness was measured using a projecting microscope equipped with a graduated scale of known dimension. Frozen sections $(4 \mu \mathrm{m})$ were also prepared for the first, third and fourth aortic areas indicated previously; these were stained with oil red 0 to visualize lipids.

\section{Chemical and biochemical methods}

$\alpha$-Tocopherol and retinol were determined in tissue specimens by reverse-phase high performance liquid-liquid chromatography (HPLC) as described previously for $\alpha$ tocopherol (Whitacre et al. 1987). The simultaneous determination of retinol by this procedure was accomplished by the use of a u.v.-detector $(325 \mathrm{~nm})$ immediately downstream from the spectrofluorometer used to detect $\alpha$-tocopherol. Because retinol esters were hydrolysed in the saponification of liver homogenates, this method detected total hepatic vitamin $\mathrm{A}$ as retinol; results are expressed in this manner. Total plasma cholesterol was determined by an enzymic (i.e. cholesterol esterase, cholesterol oxidase, peroxidase-coupled) method (Sigma Chemical Co., 1987). Prothrombin time, an indicator of vitamin $\mathrm{K}$ status, was measured using a semi-automated coagulation timer (BBL Division, Becton Dickinson \& Co., Cockeysville, MD) with tissue thromboplastin (Sigma Chemical Co., St Louis, MO) by a Quick-type test. 


\section{Expt 1}

Twenty-four rabbits (twelve male, twelve female) were fed the basal diet supplemented with either a nutritionally adequate $(40 \mathrm{mg} / \mathrm{kg})$ or a high level $(2000 \mathrm{mg} / \mathrm{kg})$ of vitamin $\mathrm{E}$. After 3 weeks, balloon catheterization involving removal of the endothelium at two aortic locations was performed as described previously; one male rabbit from each group served as a sham-operated control. All rabbits were killed $35 \mathrm{~d}$ after surgery; examinations were made of the gross morphology of aortas from each of five rabbits from each treatment group.

\section{Expt 2}

Twelve rabbits were fed the basal diet supplemented with either a nutritionally adequate $(40 \mathrm{mg} / \mathrm{kg})$ or a very high level $(10000 \mathrm{mg} / \mathrm{kg})$ of vitamin E. At 2-week intervals, blood was collected from either the ear vein or femoral artery of each rabbit after an overnight fast; $\alpha$-tocopherol, retinol, cholesterol and prothrombin time were measured in these specimens. After 2-3 weeks of feeding, balloon catheterization of the mid-thoracic aortic region was performed as described previously. At $83-84 \mathrm{~d}$ after surgery, all rabbits were killed for examination of the gross morphology of the thoracic aorta, and determination of arterial $\alpha$-tocopherol and total hepatic $\alpha$-tocopherol and vitamin $\mathrm{A}$.

\section{Statistical evaluation of results}

Values were evaluated by the Student's $t$ test using a statistical analytical system on the Cornell mainframe computer (Minitab Inc., The Pennsylvania State University, University Park, PA). The multi-variate profile analysis of repeated measured was performed for plasma retinol, total cholesterol and $\alpha$-tocopherol using a statistical analysis system configured for microcomputers (Systat Inc., Evanston, IL).

\section{RESULTS}

\section{Expt 1}

Three rabbits from the control treatment group and two from the high vitamin E-treatment group died: two had adverse reactions to isofluorane gas during surgery; two developed post-surgical paralysis and were killed; one had heart failure which, on post-mortem examination, was found to be due to a congenital malformation. In the surviving rabbits, all surgical wounds healed without incident.

All balloon-catheterized rabbits showed aortic plaque formation; however, the extent of plaque formation was not affected by the dietary level of vitamin $\mathrm{E}$, as shown by the aortic morphology scores (mean (with SE): control 58 (SE 5)) ( $n 8$ ), high vitamin E 49 (SE 6) $(n 9) ; P>0.05)$. The sham-operated rabbits fed the high level of vitamin $\mathrm{E}$ had far less extensive aortic plaque than the sham-operated, control-fed rabbits (scores 32.8 v. $50 \cdot 0$ respectively).

\section{Expt 2}

One rabbit from each treatment group died : one during surgery and the other from mucoid enteropathy. Three rabbits from the control group and one from the high vitamin Etreatment group chewed out the sutures from the skin over their wounds. These were resutured and further problems were prevented by using Elizabethan neck collars. With these exceptions, all surgical wounds healed without incident.

The vitamin E status of control rabbits was apparently adequate, as indicated by their plasma levels of $\alpha$-tocopherol, which were consistently in the range of $20-40 \mu \mathrm{g} / \mathrm{ml}$ (Fig. 1(a)). The high dietary level of vitamin E significantly $(P<0.05)$ increased $\alpha$-tocopherol levels of femoral arterial and hepatic tissues as well as plasma (Table 2). Plasma $\alpha-$ 

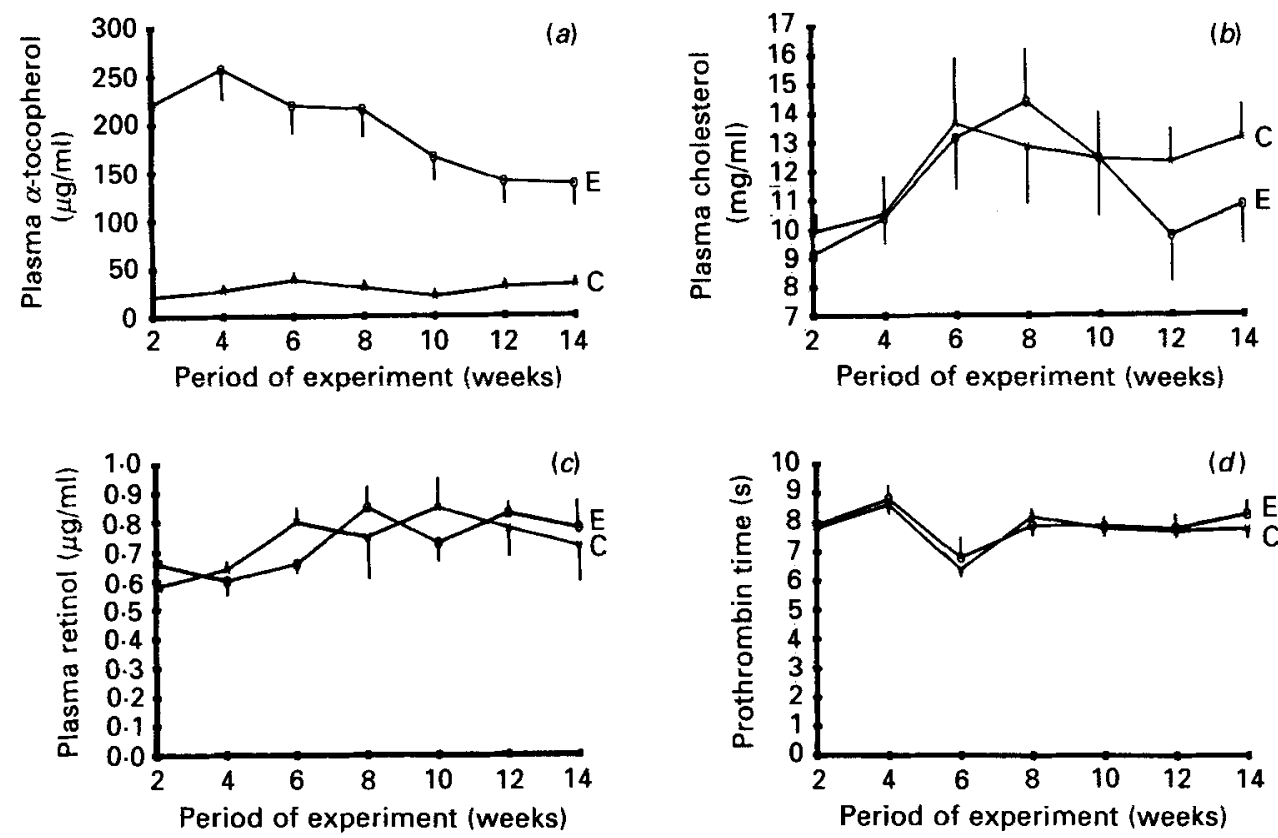

Fig. 1. Expt 2. Selected biochemical variables in rabbits fed on the control vitamin $\mathrm{E}(40 \mathrm{mg} / \mathrm{kg} ; \mathrm{C})$ or high vitamin E $(10000 \mathrm{mg} / \mathrm{kg} ; \mathrm{E})$ diets. Points are mean values with their standard errors represented by vertical bars $(n 5)$. (a), Plasma $\alpha$-tocopherol level; the time-related decline in plasma $\alpha$-tocopherol level of the high vitamin E group was significant $(P<0.01) ;(b)$, plasma total cholesterol levels; $(c)$, plasma retinol levels; the treatment effect was not significant at any time point $(P>0.05) ;(d)$, prothrombin times; the treatment effect was not significant at any time point $(P>0.05)$.

Table 2. Expt 2. Effect of a high dietary level of vitamin $E$ on tissue levels of vitamins $E$ and $A$ in rabbits

(Mean values with their standard errors for five rabbits per treatment)

\begin{tabular}{|c|c|c|c|c|c|c|}
\hline \multirow{3}{*}{$\underset{(\mathrm{mg} / \mathrm{kg})}{\text { Dietary vitamin }} \mathrm{E}_{+}^{+}$} & \multicolumn{4}{|c|}{$\alpha$-Tocopherol* $(\mu \mathrm{g} / \mathrm{g})$} & \multirow{2}{*}{\multicolumn{2}{|c|}{$\begin{array}{c}\text { Liver vitamin } \mathrm{A} \dagger \\
(\mu \mathrm{g} / \mathrm{g}) \S\end{array}$}} \\
\hline & \multicolumn{2}{|c|}{ Liver } & \multicolumn{2}{|c|}{ Femoral artery } & & \\
\hline & Mean & $\mathrm{SE}$ & Mean & $\mathrm{SE}$ & Mean & $\mathrm{SE}$ \\
\hline 40 & $37 \cdot 0$ & $4 \cdot 6$ & $21 \cdot 5$ & $4 \cdot 5$ & $260 \cdot 7$ & $33 \cdot 7$ \\
\hline 10000 & $618 \cdot 6$ & 25.8 & 167.0 & $35 \cdot 1$ & $179 \cdot 0$ & $23 \cdot 6$ \\
\hline
\end{tabular}

* Treatment effect was significant $(P<0 \cdot 05)$.

$\dagger$ Treatment effect was not significant $(P>0.05)$.

$\$$ Provided as all-rac- $\alpha$-tocopheryl acetate supplemented to the basal diet (see Table 1).

$\$$ Measured and expressed as $\mu \mathrm{g}$ retinol.

tocopherol was elevated throughout the experiment to levels as high as 257 (SE 23) $\mu \mathrm{g} / \mathrm{ml}$, but showed a significant $(P<0.01)$ decrease with time; nevertheless, at the termination of the experiment this variable was still four times the control level, i.e. 137 (SE 22) $\mu \mathrm{g} / \mathrm{ml}$.

Throughout most of the experiment, the high dietary level of vitamin $\mathrm{E}$ did not affect plasma total cholesterol level significantly $(P>0.05)$ (Fig. 1(b)); however, at the last time point tested, it reduced $(P<0.05)$ the plasma cholesterol level by about $18 \%$ from that of 
Table 3. Expt 2. Effect of a high dietary supplement of vitamin $E$ on aortic endothelial damage and plaque formation in rabbits

(Mean values with their standard errors for five rabbits per treatment)*

\begin{tabular}{|c|c|c|c|c|c|c|c|c|c|c|c|c|}
\hline \multirow{3}{*}{$\begin{array}{c}\text { Vitamin } E \ddagger \\
(\mathrm{mg} / \mathrm{kg})\end{array}$} & \multirow{2}{*}{\multicolumn{2}{|c|}{$\begin{array}{l}\text { Endothelial } \\
\text { loss } \S(\%)\end{array}$}} & \multirow{2}{*}{\multicolumn{2}{|c|}{$\begin{array}{c}\text { Plaque } \\
\text { area } \|(\%)\end{array}$}} & \multicolumn{8}{|c|}{ Maximal plaque thickness ( $\mathrm{mm}$ ) by site $\dagger$} \\
\hline & & & & & \multicolumn{2}{|c|}{ A } & \multicolumn{2}{|c|}{ B } & \multicolumn{2}{|c|}{$\mathrm{C}$} & \multicolumn{2}{|c|}{ D } \\
\hline & Mean & SE & Mean & SE & Mean & SE & Mean & SE & Mean & SE & Mean & SE \\
\hline 40 & 22 & 5 & 44 & 6 & $2 \cdot 0$ & 0.8 & $0 \cdot 9$ & 0.4 & $5 \cdot 0$ & $1 \cdot 0$ & $2 \cdot 0$ & 0.9 \\
\hline 10000 & 54 & 76 & 73 & 9 & 8.0 & $1 \cdot 3$ & $4 \cdot 0$ & $1 \cdot 1$ & 60 & 0.7 & 2.0 & 0.6 \\
\hline
\end{tabular}

Site $\mathrm{A}$, arch; site B, above mechanically injured area; site $\mathrm{C}$, in mechanically injured area; site $\mathrm{D}$ below mechanically injured area.

* Mean values were significantly different from control value: $P<0.05$

$\dagger$ For details see p. 610 .

\# Provided as all-rac- $\alpha$-tocopheryl acetate supplemented to the basal diet (see Table 1).

$\S$ Percentage total aortic area stained with Evans blue; for details, see p. 610.

|| Percentage total aortic area stained with oil red 0 ; for details, see p. 610 .

the control. The high dietary level of vitamin $\mathrm{E}$ did not significantly affect $(P>0.05)$ plasma retinol level (Fig. 1(c)), prothrombin time (Fig. 1(d)) or, by the conclusion of the experiment, total hepatic vitamin A content (Table 2).

Examination of the gross appearance of the aortas after appropriate staining revealed that the high dietary level of vitamin $E$ significantly increased $(P<0.05)$ both aortic deendothelialization (i.e. Evans blue-staining) and atherosclerotic plaque formation (i.e. Sudan III-staining) (Table 3). These effects were particularly apparent in the region of the aortic arch and area above the site of surgical damage to the intima. Histological examination of selected aortic sections revealed that the high dietary level of vitamin $\mathrm{E}$ significantly increased $(P<0.05)$ the maximal plaque thickness in both the arch and the area cephalic to the site of balloon injury (Table 3; Plates 1 and 2). That treatment, however, did not significantly affect $(P>0.05)$ maximal plaque thickness in the catheterized areas of the aorta or in the area caudal to balloon injury (through which the cannula passed). Sudan III-stained frozen sections confirmed the presence of diffuse lipid deposits of varying density throughout the plaques.

\section{DISCUSSION}

These experiments involved effects of dietary supplements of vitamin $E$ in great excess of levels having nutritional significance. The control diet was formulated to contain an adequate amount of vitamin $\mathrm{E}$; that it did was confirmed by actual analysis of the diet and by finding plasma $\alpha$-tocopherol levels in the range $20-40 \mu \mathrm{g} / \mathrm{ml}$ (Expt 2). Vitamin E supplements to the diet constituted fifty and 250 times the vitamin E requirement of the rabbit (National Research Council, 1977) in Expts 1 and 2 respectively.

In the first experiment, no evidence of alteration in either the incidence or extent of atherosclerotic plaque formation was observed in balloon injured rabbits due to the high level (i.e. fifty times the requirement) of vitamin E. Some evidence of a reduction by that level of vitamin $E$ in the extent of plaque was noted in a sham-operated rabbit; however, no inference can be made from this single observation.

Because Wilson et al. (1978) and Westrope et al. (1982) found that the supplementation of the diets of hypercholesterolaemic uninjured rabbits with $10000 \mathrm{mg}$ vitamin $\mathrm{E} / \mathrm{kg}$ diet 
for several months decreased atherosclerotic plaque formation, the second experiment of the present study was conducted using a higher level $(10000 \mathrm{mg} / \mathrm{kg})$ of vitamin $\mathrm{E}$ and a longer post-surgical period (12 weeks) than those used in Expt 1 . However, the results of the second experiment were in marked contrast with those of Wilson et al. (1978) and Westrope et al. (1982); the high-level vitamin E supplement significantly increased the extent of spontaneous aortic de-endothelialization and plaque formation, i.e. in noninjured areas. In contrast to expectation, the high vitamin $\mathrm{E}$ treatment produced no significant effects either on endothelial repair or the formation of plaque within the areas of surgical de-endothelialization.

Minick et al. (1977) found that, in balloon injured aortas of hypercholesterolaemic rabbits, lipid accumulated preferentially in endothelial repopulating areas of the intima. The trapping of lipid in the lesion during re-endothelialization is consistent with the results of the present study in which the aortic areas that stained darkly with Evans blue (i.e. were poorly re-endothelialized) were found to stain lightly with Sudan III. These areas included the mid-thoracic one intentionally damaged by ballooning, and the aortic arch in which damage was spontaneous, as the catheter was never passed into this area. The assumption that the presence of both diffuse Evans blue-staining and moderate Sudan III-staining is indicative of the re-endothelialization of a previously damaged area (Minick et al. 1977), combined with the finding of increased intimal thickness in the thoracic arches of aortas of high vitamin E-treated rabbits (i.e. in regions subject to substantial shear stresses), suggests that the vitamin E supplement promoted endothelial cell loss or inhibited endothelial cell regeneration, or both.

Because the intima is composed of endothelial cells bound to the media by collagen fibres (Shepard \& Van Houtte, 1980), and because supplements of vitamin E administered directly to wounded tissue have been found to reduce collagen synthesis (Ehrlich et al. 1972), it is possible that massive dietary levels of vitamin $E$ increased tissue $\alpha$-tocopherol levels and caused a reduction in intimal collagen production with consequent impairment in endothelial cell attachment. Loss of endothelial cells would be expected to lead to platelet aggregation and to further vessel damage including lipid deposition and, ultimately, atherosclerosis (Ross \& Glomset, 1978). According to this hypothesis, very high levels of vitamin E may potentiate the effects of factors, such as shear stress and hyperlipidaemia, that promote endothelial injury and detachment, thus resulting in increased plaque formation.

In contrast to the findings of others (Wilson et al. 1978; Westrope et al. 1982), the high level of vitamin $\mathbf{E}$ used in Expt 2 did not produce substantial reductions in the circulating total cholesterol levels, although a modest $(18 \%)$ reduction was detected at the end of the experiment. The previous studies used atherogenic diets containing high levels $(19 \%)$ of either butter (Wilson et al. 1978) or coconut oil (Westrope et al. 1982) which produced, after many months of feeding, serum cholesterol levels as high as 2910 (SE 450) and 5740 (SE 2830 ) $\mathrm{mg} / \mathrm{l}$ respectively. These levels were generally less than half those produced by the cholesterol-supplemented basal diet used in the present study (e.g. in Expt 2, rabbits fed on the control diet for 3 months had plasma cholesterol levels of $13110(\mathrm{SE} \mathrm{1220)} \mathrm{mg} / 1)$. Thus, it is possible that, in the present study, any cholesterol-lowering effect of vitamin $E$ was largely overcome by the high dietary cholesterol level that was used.

Each of the high dietary levels of vitamin E employed in the present study was above that (i.e. twenty times the nutritional requirement) presumed by the National Research Council (1987) to be safe for most animals, based on limited information from studies with chicks and rats. While it is not clear what amounts of vitamin $E$ above this level may be overtly toxic, such high levels have been shown to impair the utilization of other fat-soluble nutrients including vitamins D (March et al. 1973; Yang \& Desai, 1977 a; Alam \& Alam, 
1981; Murphy et al. 1981) and K (March et al. 1973). Although the level of vitamin E used in the second experiment of the present study was 250 times the requirement level of the rabbit, no evidence of impaired utilization of vitamins $\mathrm{A}$ or $\mathrm{K}$ was obtained, i.e. no significant effects were detected on hepatic vitamin A stores or plasma retinol level or on prothrombin time. That this high level of vitamin $E$ did not produce substantial lipid malabsorption for at least 10 weeks, is also suggested by the finding that its effect in reducing plasma cholesterol level was not significant until that time.

In contrast to the studies of Wilson et al. (1978) and Westrope et al. (1982), Bruger (1945) found that vitamin $\mathrm{E}$ administered intramuscularly $(300 \mathrm{mg} /$ week for 12 weeks) to cholesterol-fed ( $3 \mathrm{~g} /$ week) rabbits increased the aortic deposition of cholesterol almost $2 \cdot 5$ fold, thus contributing to an increase in plaque formation. In a similar study, with rabbits receiving $15 \mathrm{~g}$ cholesterol/week for 8 weeks, Moses et al. (1952) found that vitamin $\mathrm{E}$ (175 mg/week, intramuscularly) increased the extent of aortic atherosclerotic lesions. These results, as well as those of the present study, show that very high levels of vitamin E can potentiate aortic damage in animals also given very high levels of cholesterol even when it does not greatly affect circulating cholesterol levels. In contrast, the results of Wilson et al. (1978) and Westrope et al. (1982) show that, in animals with lower circulating cholesterol levels, high levels of vitamin E can reduce both those levels and the extent of atherosclerosis. These several findings, therefore, suggest that the effects of very high levels of vitamin $E$ on atherosclerotic plaque formation can be quite different depending on cholesterol status.

The authors gratefully acknowledge the valuable assistance rendered by the following people: Drs J. M. King, L. P. Krook and B. A. Summers, Department of Pathology, New York State College of Veterinary Medicine, and Dr C. R. Minick, Department of Pathology, Cornell University Medical School, for their advice and assistance in the conduct of the histological evaluations; Dr D. Schwenke for technical advice concerning the catheterization procedure; Ms L. P. Deuschle and Ms T. Smith for assistance in the biochemical and histological procedures; $\mathrm{Mr} \mathrm{T}$. J. Grant and $\mathrm{Mr} \mathrm{H}$. Redder for animal care. This study was supported in part by grants from BASF Corp., Parsippany, NJ, and Hoffmann-La Roche, Inc., Nutley, NJ.

\section{REFERENCES}

Alam, S. Q. \& Alam, B. S. (1981). Effects of excess vitamin E on rat teeth. Calcified Tissues International 33, 619-624.

Baker, J. L. (1981). The effectiveness of alpha-tocopherol (vitamin E) in reducing the incidence of spherical contracture around breast implants. Plastic Reconstructive Surgery 68, 696-698.

Bruger, M. (1945). Experimental atherosclerosis. VII. Effect of vitamin E. Proceedings of the Society for Experimental Biology and Medicine 59, 56-57.

Chan, A. C., Raynor, C., Douglas, C., Patrick, J. \& Boland, M. (1986). Transitory stimulation of platelet $12-$ lipoxygenase by vitamin E supplementation. American Journal of Clinical Nutrition 44, 278-282.

Chen, L. H., Liao, S. \& Packett, L. V. (1972). Interaction of dietary vitamin E and protein level or lipid source with serum cholesterol level in rats. Journal of Nutrition 102, 729-732.

Depalma, R. G., Hubay, C. A., Insull, W., Robinson, A. G. \& Hartmen, P. M. (1970). Progression and regression of experimental atherosclerosis. Surgical and Gynaecological Obstetrics 131, 633-647.

Donaldson, W. E. (1982). Atherosclerosis in cholesterol-fed Japanese quail: evidence for amelioration by dietary vitamin E. Poultry Science 61, 2097-2102.

Dunphy, J. E. (1974). Modern biochemical concepts on the healing wound. In Medcom Medical Update Series - Wound Healing, pp. 22-31 [J. E. Dunphy, editor]. New York: Medcom Press.

Ehrlich, H. P., Tarver, H. \& Hunt, T. K. (1972). Inhibitory effects of vitamin E on collagen synthesis and wound repair. Annals of Surgery $175,235-240$.

Fong, J. S. C. (1976). Alpha-tocopherol: its inhibition of human platelet aggregation. Experientia 15, 641-693.

Forester, W. (1980). In vivo and ex vivo studies of the effect of vitamin E pretreatment on PGA and TXA synthesis. Acta Medica Scandinavica 642, Suppl., 47-48. 
Friedman, M. \& Byers, S. O. (1965). Aortic atherosclerosis intensification in rabbits by prior endothelial denudation. Archives of Pathology 79, 345-356.

Heinecke, J. W., Baker, L., Rosen, H. \& Chait, A. (1986). Superoxide-mediated modification of low density lipoprotein by arterial smooth muscle cells. Journal of Clinical Investigation 77, 757-761.

Holman, R. L., McGill, H. C., Strong, J. P. \& Geer, J. C. (1958). Techniques for studying atherosclerotic lesions. Laboratory Investigation 7, 42-77.

Kagoma P., Burger, S. N., Seifter, E., Levenson, S. M. \& Demetriou, A. A. (1985). The effect of vitamin E on experimentally induced peritoneal adhesions in mice. Archives of Surgery 120, 949-951.

Kamimura, M. (1972). Anti-inflammatory activity of vitamin E. Journal of Vitaminology 18, $204-209$.

Karpen, C. W., Merola, A. J., Trewyun, R. W., Cornwall, D. G. \& Panganamal, R. V. (1981). Modulation of platelet thromboxane $\mathrm{A}_{2}$ and arterial prostacyclin by dietary vitamin E. Prostaglandins 22, 651-661.

Kim, J. E. \& Shklar, G. (1983). The effect of vitamin E on the healing of gingival wounds in rats. Journal of Periodontology 54, 305-308.

Komaratat, P., Chupukcharoen, N. \& Wilairat, P. (1985). Effect of vitamin E on cholesterol plasma lipoprotein distribution and metabolism in rabbits. International Journal of Vitamin Nutrition Research 55, 167-171.

Lee, M. (1953). An investigation into the value of D,L-alpha-tocopheryl acetate (vitamin $E$ ) in the treatment of gravitational ulcers. British Journal of Dermatology 65, 131-138.

Lucy, J. A. (1978). Structural interactions between vitamin E and polyunsaturated phospholipids. In Tocopherol, Oxygen and Biomembranes, pp. 109-120 [C. de Duve and O. Hayaishi, editors]. New York: Elsevier/North Biochemical Press.

March, B. E., Wong, E., Seier, L., Sim, J. \& Biely, J. (1973). Hypervitaminosis E in the chick. Journal of Nutrition $103,371-377$.

Marks, J. (1962). Critical appraisal of the therapeutic value of alpha-tocopherol. Vitamins and Hormones 20, 573-598

Minick, C. R., Stermerman, M. B. \& Insull, W. (1977). Effect of regenerated endothelium on lipid accumulation in the arterial wall. Proceedings of the National Academy of Sciences, USA 74, 1724-1728.

Moses, C., Rhodes, G. L. \& Levinson, J. P. (1952). The effect of alpha-tocopherol on experimental atherosclerosis. Angiology 3, 397-398.

Murphy, T. P., Wright, K. E. \& Pudelkiwicz, W. J. (1981). An apparent rachitogenic effect of excessive vitamin E in the chick. Poultry Science 60, 1873-1878.

National Research Council (1977). Nutrient Requirements of Rabbits, p. 15. Washington, DC: National Academy Press.

National Research Council (1987). Vitamin E. Vitamin Tolerance of Animals, pp. 23-30. Washington, DC: National Academy Press.

Okuma, M., Steiner, M. \& Bablini, M. (1971). Studies on lipid peroxides in platelets. Journal of Laboratory and Clinical Medicine 77, 728-742.

Okuma, M., Takayama, H. \& Uchino, H. (1980). Generation of prostacyclin-like substance and lipid peroxidation in vitamin E-deficient rats. Prostaglandins 19, 527-536.

Ross, R. \& Glomset, J. A. (1978). The pathogenesis of atherosclerosis. New England Journal of Medicine 295, 420425

Schwenke, D. (1985). Cholesterol ester influx, loss, accumulation in injured and noninjured aorta of hypercholesterolemic rabbits, p. 165. PhD Thesis, Cornell University, Ithaca, NY.

Shepard, J. T. \& Van Houtte, P. M. (1980). The Human Cardiovascular System. Facts and Concepts, p. 223. New York: Raven Press.

Sigma Chemical Co. (1987). Sigma Diagnostic Procedure no. 351. St Louis, MO: Sigma Chemical Co.

Steiner, M. (1978). Inhibition of platelet aggregation by alpha-tocopherol. In Tocopherol, Oxygen and Biomembranes, pp. 143-161 [C. de Duve and O. Hayaishi, editors]. New York: Elsevier/North Biochemical Press.

Stemerman, M. B. (1973). Thrombogenesis of the rabbit arterial plaque. American Journal of Pathology 73, 7-25.

Stuyvesant, V. W. \& Jolley, W. B. (1967). Anti-inflammatory activity of D-alpha-tocopherol (vitamin E) and linoleic acid. Nature 216, 585-586.

Viswanathan, M., Bhakthan, N. M. G. \& Rockerbie, R. A. (1979). Effect of dietary supplementation of vitamin $\mathrm{E}$ on serum lipids and lipoproteins in rabbits fed a cholesterolemic diet. International Journal for Vitamin and Nutrition Research 49, 370-375.

Westrope, K. L., Miller, R. A. \& Wilson, R. B. (1982). Vitamin E in a rabbit model of endogenous hypercholesterolemia and atherosclerosis. Nutrition Reports International 25, 83-89.

Whitacre, M. E., Combs, G. F. Jr, Combs, S. B. \& Parker, R. S. (1987). Influence of dietary vitamin E on nutritional pancreatic atrophy in selenium-deficient chicks. Journal of Nutrition 117, 460467.

Wilson, R. B., Middleton, C. C. \& Sun, G. Y. (1978). Vitamin E, antioxidants and lipid peroxidation in experimental atherosclerosis of rabbits. Journal of Nutrition 108, 1858-1867.

Yang, N. Y. J. \& Desai, I. D. (1977a). Effect of high levels of dietary vitamin E on liver and plasma lipids and fat-soluble vitamins in rats. Journal of Nutrition 107, 1418-1426.

Yang, N. Y. J. \& Desai, I. D. (1977 b). Effect of high levels of dietary vitamin E on hematological indices and fatsoluble vitamins in rats. Journal of Nutrition 107, 1410-1417. 

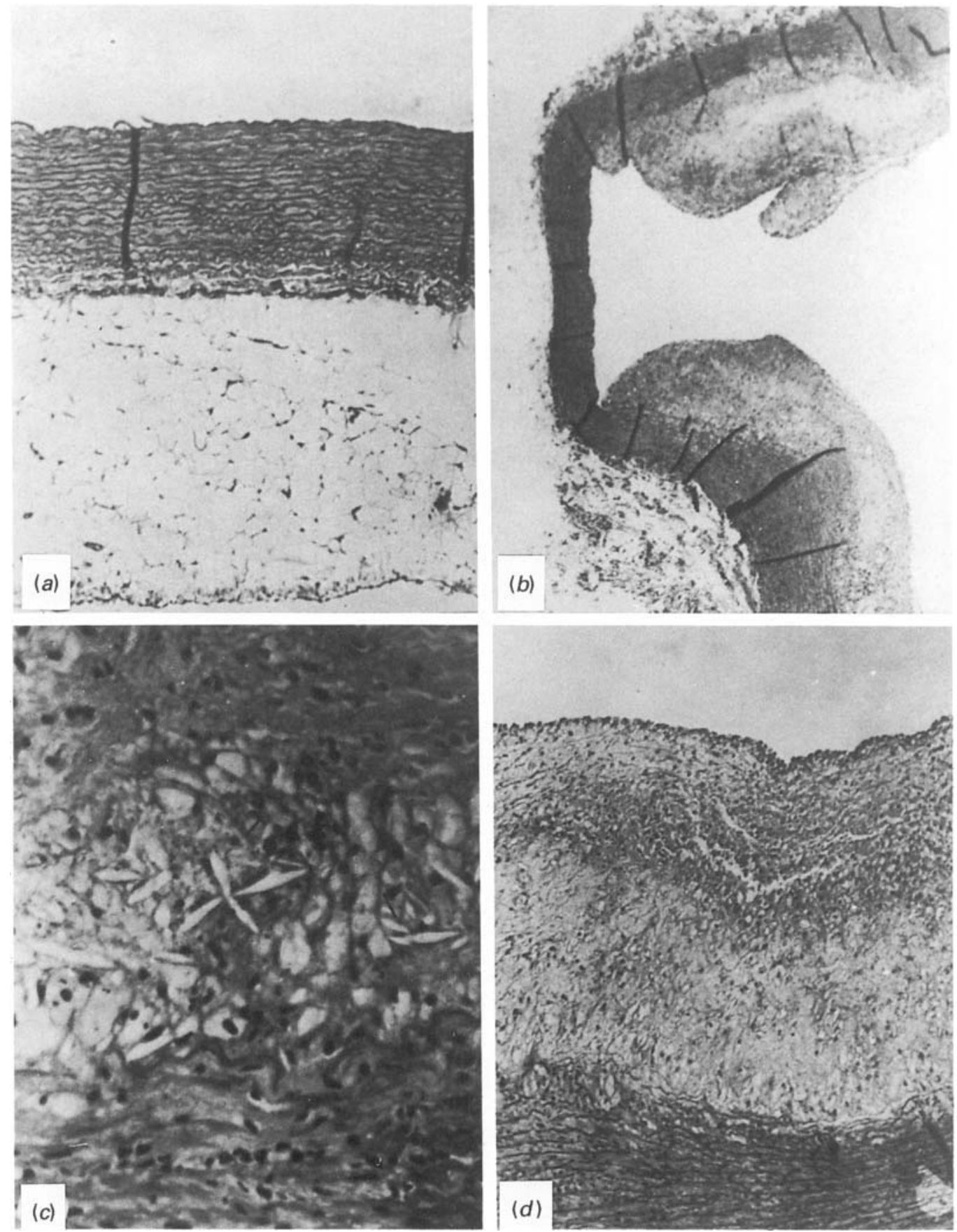

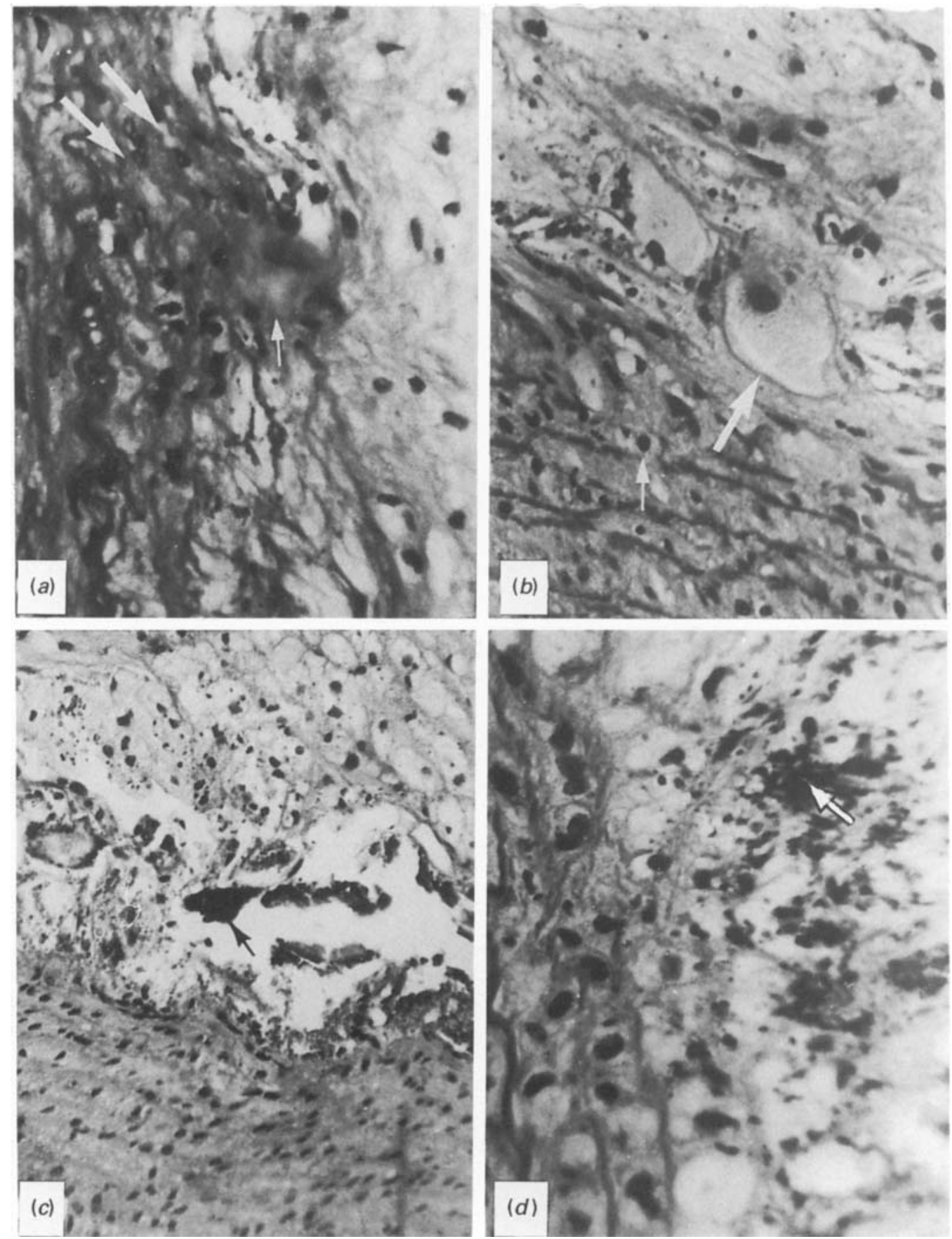


\section{EXPLANATION OF PLATES}

Plate 1. Expt 2. Histological appearance of thoracic aortas. (a), Arterial wall from a rabbit fed the control vitamin $\mathrm{E}$ diet $(40 \mathrm{mg} / \mathrm{kg}$ ) with intima (top) one cell thick; haematoxylin and eosin staining (H\&E) $\times 100$. (h), Non-continuous plaque with thickening of the intima and tunica media in atherosclerotic areas from a rabbit fed a high vitamin $\mathrm{E}$ diet $(10000 \mathrm{mg} / \mathrm{kg}) ; \mathrm{H} \& \mathrm{E} \times 30 .(\mathrm{c})$, Note the cholesterol crystals in the lower intima of a high vitamin $\mathrm{E}$ fed rabbit; H\&E $\times 300 .(d)$, Severely atherosclerotic section showing thickening of the intima of a high vitamin $\mathrm{E}$ fed rabbit; $\mathrm{H} \& \mathrm{E} \times 100$.

Plate 2. Expt 2. Histological appearance of thoracic aortas. (a), Smooth muscle cells proliferating from the tunica media into the intima from a rabbit fed a high vitamin $\mathrm{E}$ diet $(10000 \mathrm{mg} / \mathrm{kg})$; large arrows show upgrowth of cells and small arrow shows hyalinization; haematoxylin and eosin staining (H\&E) $\times 480$. (b), High vitamin $\mathrm{E}$ fed rabbit; large arrow shows smooth muscle cell filled with lipid (foam cell), small arrow shows normal smooth muscie cell; H\&E $\times 450$. (c), Control-fed $(40 \mathrm{mg}$ vitamin $\mathrm{E} / \mathrm{kg}$ diet) rabbit; arrow shows mineralization; $H \& E \times 250 .(d)$, High vitamin $E$ fed rabbit; arrow shows mineralization; H\&E $\times 480$ (with oil). 